\title{
Difficulties Associated with a Clinical Psychiatric Study of a Transient Population
}

\author{
Stephen Zerby M.D. \\ Jefferson Medical College, Thomas Jefferson University Hospital, Philadelphia, PA
}

Follow this and additional works at: https://jdc.jefferson.edu/jeffjpsychiatry

Part of the Psychiatry Commons

Let us know how access to this document benefits you

\section{Recommended Citation}

Zerby, Stephen M.D. (1999) "Difficulties Associated with a Clinical Psychiatric Study of a Transient Population," Jefferson Journal of Psychiatry. Vol. 14 : Iss. 2 , Article 2.

DOI: https://doi.org/10.29046/JJP.014.2.006

Available at: https://jdc.jefferson.edu/jeffjpsychiatry/vol14/iss2/2

This Article is brought to you for free and open access by the Jefferson Digital Commons. The Jefferson Digital Commons is a service of Thomas Jefferson University's Center for Teaching and Learning (CTL). The Commons is a showcase for Jefferson books and journals, peer-reviewed scholarly publications, unique historical collections from the University archives, and teaching tools. The Jefferson Digital Commons allows researchers and interested readers anywhere in the world to learn about and keep up to date with Jefferson scholarship. This article has been accepted for inclusion in Jefferson Journal of Psychiatry by an authorized administrator of the Jefferson Digital Commons. For more information, please contact: JeffersonDigitalCommons@jefferson.edu. 


\title{
Difficulties Associated with a Clinical Psychiatric Study of a Transient Population
}

\author{
Stephen Zerby, M.D.
}

One of the more interesting patients I evaluated as a first year Child Psychiatry fellow was a homosexual youth who made cross-dressing and dancing in the street all night with friends the focus of his life. He had a difficulty with mood control that was complicated by multiple placement failures and runaway episodes. The question put to me was how to effectively intervene in this situation given the social instability. In order to understand the patient better I had to learn more about his social group and the various problems associated with it. What I had just heard from the patient was a glimpse of life in a little-known "underground" subculture that was so fascinating and worrisome that I was tempted to initiate a research project based upon it. I found a collaborator to launch a research project intended to study the needs of this group of patients at high-risk of mental health difficulties. In the next few months we embarked on an exercise in a clinical research project in Psychiatry. The main problems we faced were those of the difficulty in accessing members of a transient population as well as legal and ethical hurdles associated with working with homeless youth.

The population to which my patient belonged was homeless inner-city "sexual minority" homosexual adolescent males allegedly living in abandoned houses under the unofficial supervision of unrelated adults who were de facto "parents." This is termed the "House" subculture (1). The youth in question were reportedly "refugees" from the supervision of official agencies due to discrimination and abuse allegedly suffered in placements (2). Moreover, they were also supposedly alienated from their families due to rejection as a result of their sexual orientation and practices. Therefore they were often alone in a big city, young, and at risk for sexual and financial exploitation. Reported problems in this population include physical illness such as sexually transmitted diseases and AIDS, mental health problems such as depression and suicide attempts, drug abuse (including hormone abuse), criminality such as forgery and credit card fraud to support themselves, and prostitution along with its associated problems $(1,3,4)$. One of the most fascinating aspects of this group was the subculture that they have created for themselves, cross-dressing in fairly well-organized fashion shows termed "balls" in which "houses" compete against each other, akin to team sports. Reportedly members of "houses" engage in criminal activity to support the cost of wardrobe, makeup, and the "ball" itself (1). In return for their participation members of "houses" receive shelter, emotional support, camaraderie, and some sense of acceptance $(1,5)$. What was apparently before us was a supportive subculture that replaced conventional society to support a vulnerable 
group of young people. Clearly this was a population in need of help and further study, if the youths themselves were able and willing to participate and seek help.

We wanted to determine the prevalence of medical, psychiatric, abuse, and legal difficulties in this group to then make a determination of the nature and extent of services that would be needed. The data would be obtained through anonymous surveys, interviews, and focus groups. The information obtained would then be used as a measure of pathology in these adolescents. A literature search revealed little information about this particular population but studies of homeless youth in general determined that there is a high rate of psychiatric $(4,6,7,8)$ and physical $(9,10,11)$ illness among them; they seemed to be underserved in terms of physical and mental health treatment $(8,12)$. Our results would then be used to make a case for the creation and implementation of any needed physical and mental health services.

We needed access to and cooperation from the study population, but this proved to be complicated. This subculture tends to have very limited contact with family and the rest of society. My collaborator had had contact with some individuals in this subculture through different clinics and they were a source of information about this group. We hoped these clinics and their clients would be willing to participate in our study. We wanted to perform chart reviews, interviews, groups, and questionnaires using a clinical population at a local mental health facility that provided services to sexual minority youth. We would then use serial measures such as the Brief Psychiatric Rating Scale (BPRS) (13) to measure the outcome of the program and the progress of the clients. Our results would reflect only those participants who did attend that particular mental health clinic and who would agree to be open about their problems. A question that had to be answered was just how much help or even contact with the outside world these patients wanted. My patient whom I had consulted on seemed more than happy to have foregone society altogether rather than become reintegrated, casting cloudiness upon our thesis that if we determined that there existed a need for a specialty service such as a group home for sexual minority youth, that the demand would also exist. There was no guarantee or even strong evidence that if our project goals were explained to the potential participants that they would agree to cooperate with us. There was also no guarantee that they would accept any conclusions that they were in need of various services and would accept them. Even though the solutions that would be proposed as a result of our study might sound reasonable to the investigators, they might not to independenceminded adolescents who had had harsh experiences with families, agencies, and society. Voluntarily returning to the supervision of the authorities would be a "hard sell." Gaining the cooperation of clinics that service these youth also proved more difficult than we had anticipated, mostly due to legal and ethical dilemmas.

A legal difficulty that surfaced involved concerns over confidentiality. The first step of data collection would have been an anonymous questionnaire that surveyed pathology across a spectrum of topics such as mental health, physical health, substance abuse, abuse history, and legal problems. A positive point of an anonymous survey was that the results could not be tracked to any individual, ensuring honesty of response as well as security that the data could never surface at a later date to have 
some negative impact upon the participants. After consultation with individuals familiar with this kind of project, even an anonymous questionnaire would still have to include a signed informed consent form that would be kept separate from the actual questionnaire. Any data, especially given the controversial nature of our population, would have to be guarded and all steps taken to ensure confidentiality. The exact security measures would have to be explicitly explained in any grant proposals as well as to the participating youths in order to ensure honest and open responses and accurate results. Interviews and focus groups are much more difficult to gain approval for because the data would be associated with a known individual. Our population, according to our sources, was very wary of contact with official organizations and those who did participate in the study might become guarded once any identifying data were used since some of their problems, especially legal problems, once revealed, could have negative consequences unless kept strictly confidential. The need for careful explanation of the project, its goals, and any steps taken to ensure the participants safety are crucial in working with a population such as this one.

Another complication were the legal and ethical problems associated with abuse histories in a juvenile population. Obtaining an abuse history from these patients led to a curious dilemma. Many of our potential subjects had had previous encounters with various placements and allegedly found that being placed in foster homes and group homes subjected them to discrimination and even emotional and physical abuse. They were therefore apparently afraid to fall back under the supervision of any official agency or to cooperate with the "system" and likewise chose to live in this underground "house" environment where they allegedly felt more accepted and safe. The dilemma was partially one of liability: if tales of abuse were heard, how would we approach the obligation to report these allegations to the authorities? If only anonymous questionnaires were used, there would be no way of officially knowing which subject reported the abuse. Also, without an official address, as the subjects were living in an "underground" setting, investigation would be difficult. There most likely would not be a name or address of the alleged abusers to report. We were told that if the authorities were mentioned, the participants would not reveal instances of abuse due to their fear of intervention by the authorities and the so-called "system," which would then defeat the purpose of the investigation to discover abuse in the first place. Not only was there a professional dilemma of the legal liability of failing to report abuse of a minor, there was also an ethical one. How could an investigator learn of a history of unaddressed abuse, past or present, and do nothing about it at the request of the abused person? One would worry how imminently intervention was needed and whether participation in a project with only potential benefits, rather than immediate, would be enough to relieve any angst that might be felt by the investigators. Due to these reasons, a project such as ours had inherent problems that might prevent its authorization by both patients and by any institution with whom we might have wished to collaborate. It seemed puzzling to think that there could exist a population of minors on the fringe of society who would remain unknown, their needs unaddressed, because of insurmountable legal and ethical hurdles to their study. 
Even though a project such as ours may sound entirely feasible at the outset, there is no guarantee that all parties involved-investigators, participants, clinics, consultants - will agree on the terms and conditions of the study. In the case of studying the needs of transient youth special considerations must be made. On several occasions while discussing this project with a supervisor or a colleague, the question was put to me whether the targeted youth even wanted our services or whether they were satisfied in their present situation. I usually approached this question from an "adult" point of view: that these adolescents may be missing a great deal and our job as adults and professionals is to guide them to a more abstract, reflective, and well-rounded way of thinking. There are very good reasons for the age limits and designations as minors that society imposes as well as the caretaking role for which adults are given responsibility. Education is an inalienable part of youth and in the case of our project, education about the dangers they faced from their various issues and problems would have to be an integral theme of any intervention. They would then have the ability to make informed choices rather than simply choices whether to accept any interventions offered to them. As growing adolescents they must continue to learn how to make decisions regarding their own health and safety, although in this population the risks of making choices that may endanger them are quite high. The legal and ethical hurdles to providing such assistance are similarly a result of the rules and standards imposed upon us by society and as an example to our younger patients, we must abide by and work within those guidelines. There is the hope that even if these rules seem unreasonable eventually their wisdom will become clear and we will be able to work with our patients effectively.

\section{REFERENCES}

1. Mullins J: A House Is Not a Home. Au Courant 1998. Vol. 2 (Issue 18), pp 3-17.

2. Wolfson J: Gay Youth Find Safe Haven in GLASS Houses. Youth Today 1998. Vol. 7 (No. 7), pp 1,34-37.

3. Rotheram-Borus MJ, Meyer-Bahlburg HFL, Rosario M, Koopman C, et al: Lifetime sexual behaviors among predominantly minority male runaways and gay/bisexual adolescents in New York City. The Guilford Press: AIDS Education and Prevention, Supplement, Fall 1992, pp 34-42.

4. Kruks G: Gay and lesbian homeless/street youth: Special issues and concerns. J Adol Health 1991; 12:515-518.

5. Mallon G: Gay and no place to go: Assessing the needs of gay and lesbian adolescents in out-of-home care settings. Child Welfare 1992; 71:547-556.

6. Booth RE, Zhang Y: Severe aggression and related conduct problems among runaway and homeless adolescents. Psychiatric Services 1996; 47:75-80.

7. Sleegers J, Spijker J, van Limbeck J, et al: Mental health problems among homeless adolescents. Acta Psychiatr Scand 1998; 97:253-259.

8. Rotheram-Borus MJ, Rosario M, Reid H, et al: Predicting patterns of sexual acts among homosexual and bisexual youths. Am J Psychiatry 1995; 152:588-595.

9. Porto SOB, Cardoso DDP, Queiroz DAO, et al: Prevalence and risk factors for HBV infection among street youth in central Brazil. J Adol Health 1994; 15:577-581. 
10. Ensign J, Santelli J: Health Status and Service Use. Arch Pediatr Adolesc Med 1998; 152:20-24.

11. Creatsas GK: Sexuality: sexual activity and contraception during adolescence. Curr Op Ob Gyn 1993; 5:774-783.

12. Goodman E, Berecochea JE: Predictors of HIV testing among runaway and homeless adolescents. J Adol Health 1994; 15:566-572.

13. Kutcher SP: Brief Psychiatric Rating Scale, in Child and Adolescent Psychopharmacology. Philadelphia, WB Saunders, 1997, p 435. 